\title{
Teaching Reform of Environmental Impact Assessment Course Focusing on Practical Ability Training
}

\author{
Haixia Wang ${ }^{\mathrm{a}}$, Mingliang Zhang ${ }^{\mathrm{b}}$ \\ School of Water Conservancy and Environment, University of Jinan, Jinan 250022, China \\ astu_wanghx@ujn.edu.cn, bstu_zhangml@ujn.edu.cn
}

\begin{abstract}
The environmental impact assessment course is a comprehensive and practical course for environmental science and engineering major. Environmental impact assessment is also an important employment direction for environmental science and engineering students after graduation. Continuous research on the teaching reform of this course is necessary for cultivating talents with strong creativity and practical ability. Based on the analysis of the current situation of the course teaching, it is proposed to update content of course, appropriately increase class hours, highlight the case-based practice teaching, clarify the teaching goals, highlight the direction of employment (environmental impact assessment engineers), focus on cultivating application and innovation capabilities, reform achievement assessment methods and other corresponding measures and solutions.
\end{abstract}

Keywords: Environmental Impact Assessment; Teaching Reform; Practice; Innovation.

\section{Introduction}

Environmental impact assessment (EIA) is a compulsory course of environmental science and engineering major, which has the characteristics of professional comprehensiveness and strong practicality. The teaching goal of this course for students is to master the basic theories and methods of environmental impact assessment and EIA reports document preparation [1]. In addition to the theoretical knowledge, the EIA course requires students to pay attention to the changes in relevant laws, regulations and policies, grasp the latest policies and technical guidelines related to EIA. Furthermore, EIA course teaching should emphasize on practicality and application of environmental impact assessment to serve the social production practice [2]. However, the current EIA course teaching process generally has the problem of emphasizing theory and neglecting practice, and does not pay attention to cultivating students' ability to solve actual environmental problems. The teaching goal of this course cannot be achieved only by teaching theory in classroom teaching. Therefore, exploring effective practical teaching models in the teaching process, cultivating students' practical application ability and innovative ability in EIA to lay the foundation for EIA application after graduation, have become the key directions of the EIA course teaching reform [2].

\section{The Current Situation of EIA Course Teaching}

\subsection{Textbook Contents are Lagging behind the Reality}

In the past five years, the EIA related policies and guidelines have undergone significant changes. The "Environmental Impact Assessment Law" was amended twice in 2016 and 2018. At the same time, the related EIA regulations, guidelines, and standards are frequently updated. For example, the "Technical Guidelines for Environmental Impact Assessment of Construction Projects-General Outline" and "Technical Guidelines for Environmental Impact Assessment of Construction ProjectsGroundwater Environment" were revised in 2016. The "Technical Guidelines for Environmental Impact Assessment" Environment" (HJ2.2-2018), "Technical Guidelines for Environmental Impact Assessment, Surface Water Environment" (HJ2.3-2018) and "Technical Guidelines for Environmental Risk Assessment of Construction Projects" (HJ169-2018), and the "Environmental Technical Guidelines for Impact Assessment Soil Environment (for Trial Implementation)" (HJ964- 
2018) were issued in 2018; The drafts for comments on "Guidelines for Noise Environmental Assessment" and "Guidelines for Ecological Environmental Assessment" were also released.

At present, the textbooks related to EIA include the "Environmental Impact Assessment" published by Huazhong University of Science and Technology Press in 2012, the "Environmental Impact Assessment" published by Science Press in 2008, and the "Environmental Impact Assessment" textbook published by Higher Education Press in 2004. The latest textbook is "Environmental Impact Assessment (Second Edition)" published by Chemical Industry Press in 2018. However, compared with the rapidly updated EIA technical guidelines, standards and other related environmental protection laws and regulations, these textbooks are obviously lagging behind the reality. The introduction of laws and regulations, technical guidelines, standards and methods in the textbooks are not consistent with the updated laws and regulations. It will be difficult for students to understand the current latest EIA policies, technical guidelines, standards and methods, and fail to meet the requirements for environmental assessment engineer, through learning using the current textbooks.

\subsection{Unclear Teaching Goal}

At present, for most of EIA textbooks, the teaching goal is to predict the environmental impact of construction project, and propose measures to avoid or mitigate adverse impacts on environment, based on a comprehensive analysis of environmental status, pollution source survey and assessment. The application characteristics of EIA and the importance of learning this course are not fully emphasized. Many students do not understand the meaning of learning EIA.

\subsection{Teaching Focus is Not in Line with Reality}

According to the survey, the relevant personnel believe that the application of EIA related laws, regulations and standards, the application of assessment methods, the application of technical guidelines, the identification and screening of environmental impact factors, and environmental impact prediction assessment, and EIA report writing skills are the key application aspects of environmental quality assessment work. The existing teaching content often divides the teaching time by chapters, focusing on the explanation of the relevant concepts, knowledge, and basic theories of environmental quality assessment. However, the teaching process does not integrate actual cases well, and fails to combine theory with practice. The ability to highlight case analysis and the writing skills of EIA reports is often neglected, and the teaching focus cannot meet the actual needs of society.

\subsection{Insufficient Class Hours and Weak Practice Links}

The classroom teaching of EIA course is 32 class hours. Compared with the comprehensive and complicated knowledge system of EIA, it is difficult to completely clarify the basic knowledge in 32 hours. EIA is a very practical course, so the teaching should combine theory and actual cases in the teaching process. It can expand students' horizons and stimulate students' interest in learning. At present, this aspect is relatively weak, and lack of close connection with reality.

\section{Discussion on the Teaching Reform Method of EIA Course}

\subsection{Timely Supplement and Update, Optimize Teaching Contents}

The existing teaching system should be updated to improve the teaching mode while ensuring the knowledge points of the syllabus, to integrate theory and practice. The latest published teaching materials should be selected to ensure the validity of the teaching contents. The latest laws and regulations, technical guidelines, standards and methods related to EIA should be introduced into the classroom teaching, thus students can master latest advances in EIA. For example, for the newly issued guidelines for atmospheric environmental impact assessment, soil environmental assessment guidelines, surface water environmental assessment guidelines, and environmental risk assessment guidelines should be integrated into classroom teaching. 


\subsection{Appropriately Increase Class Hours and Highlight Case Practice Teaching}

According to EIA course content and syllabus, the course time can be appropriately increased to 36-48 class hours. More class hours can be allocated to the application of technical guidelines, identification and screening of environmental impact factors, and application of environmental protection standards to improve students' practical ability and enhance students' competition in job hunting after graduation. Through the introduction of actual engineering cases, students can be familiar with the chapter structure, content and preparation process of EIA report. Such a curriculum system will be easier to achieve the goal, and at the same time it has a positive meaning for enhancing the employment competitiveness of students. In addition, curriculum practice design should be required to enhance students' practical and innovative abilities through solving a specific practical problem. For example, taking the impact of water conservancy project construction on water ecoenvironment as example, teacher can guide students to think the case. Students can grasp the actual content of a certain water conservancy project construction and its impact on water eco-environment by consulting a large number of materials [3]. It will be essential to encourage students' participation in the classroom, improve the ability to use knowledge to solve practical problems, and cultivate students' creativity.

\subsection{Construction of Case Materials Database}

EIA course is closely related to social practice and construction, and has strong applicability and practicality. Therefore, the realization of the teaching objectives of this course is inseparable from high-quality engineering case materials in line with the real situation of production and construction. However, in the process of implementation, there are many significant problems, such as insufficient number of teaching cases, outdated cases, serious disconnection between the content and production enterprises, which seriously affect the improvement of teaching quality and the training quality of EIA engineer. It will be very important to construct EIA case material library case database based on field investigation, derived from society real engineering activity. The cases should preferably involve various typical industries (e.g., transportation construction project, domestic garbage landfill and incineration project, thermal-electricity project, hydropower project, mining and tailings pond project, Printing and dyeing project), and at least 1-2 typical cases should be designed for each industry.

\subsection{Clarify Teaching Objectives and Highlight the Employment Direction}

In the past, the teaching goal of the EIA course was to enable students to master the basic concepts, basic theories, relevant laws and standards, and procedures of environmental quality assessment. However, the significance and purpose of students' learning of this course are still not very clear. Therefore, teacher should emphasize the importance of learning EIA courses for the environmental assessment work after graduation. Teachers should demonstrate the professional value of environmental quality assessment in the course of teaching, and reflect the practicality of environmental quality assessment knowledge. For example, due to the gradual improvement of national environmental management policies, most construction projects currently require the compilation of construction project environmental assessment report. A good study of EIA courses will lay a solid foundation for the future qualification of EIA engineers, which will definitely help increase the chances of employment for environmental majors after graduation [2]. Therefore, the teaching objectives of this course in the new teaching system: train future EIA engineers who meet society needs, and carry out EIA work for the implementation of construction or planning projects.

\subsection{Combination of Classroom and Online Teaching}

The online and offline mixed teaching method is a new teaching mode and has become the key content of the current teaching reform. Considering the advantages and disadvantages of the online and offline mode, the mode of "pre-class preview-in class study-after class review" is proposed and recommended. Firstly, teachers assign learning task and design teaching resources according to 
teaching objectives, and students independently study in pre-class. In class, students need to exhibit their work in class, and deepen the exploration of knowledge under the guidance of teachers. After class, students are required to review the contents and complete online homework. In the whole process, students are encouraged to interact online or offline with each other.

\subsection{Reform Achievement Assessment Methods}

The traditional assessment method cannot fully highlight the assessment of practical innovation ability, and it is not conducive to guide the cultivation of students' practical innovation ability. For this reason, during the assessment process, more attention should be paid to practice assessment, and the proportion of assessment in curriculum design or practice should be increased. For example, teachers can provide actual case materials (test), and students are required to complete the work on the basis of reading materials or watching instructional videos and reading extended literature. The whole learning process can completely simulate the actual EIA work. Finally, teachers can give feedback and assessment to the students. Finally, combining the students' daily performance, the quality of the EIA report writing, the course design, and the final exam results, the students' final scores are calculated according to a certain proportion.

\section{Conclusion}

Based on the analysis of the current situation of the EIA course teaching, several suggestions are proposed to improve the teaching quality and realize the cultivation of environmental assessment engineer, including updating content of course (the latest technical guidelines, standards and methods related to EIA), appropriate increasing class hours, highlighting the case-based practice teaching, integrating typical engineering cases into teaching content, strengthening case analysis and discussion, highlight the direction of employment (environmental impact assessment engineers).

\section{Acknowledgments}

This work is supported by teaching case database of professional degree postgraduates in Shandong province (SDYAL20121), and teaching research project of University of Jinan (SHJY18 07).

\section{References}

[1] Zhang Chunhui, He Xuwen, Yu Caihong, et al. Current situation and improvement ideas of environmental impact assessment teaching. Environmental Science and management (China). Vol. 36 (2011), No. 11, p. $18-20$.

[2] Deng Lin, Luo Wei. Environmental impact assessment curriculum reform guided by training environmental impact assessment engineers. Journal of Higher Education (China). Vol. 131(2020), No. 9, p. $138-139$.

[3] Hu Chenyan, Zhou Zhen, Zhao Xiaodan. Analysis on the reform and innovation of "environmental impact assessment" Teaching under the new situation. Education and teaching forum (China). Vol.491(2020), No. 45, p. 162-163. 